\title{
Importância das abelhas para a biodiversidade na percepção de educandos de Cáceres, MT
}

As abelhas são importantes polinizadores, portanto fundamentais para a manutenção da biodiversidade. Entretanto, um conjunto de transformações antrópicas ao ambiente tem causado o colapso das abelhas. Esta pesquisa teve o objetivo de avaliar a percepção ambiental dos educandos de uma escola pública de grande porte de Cáceres sobre a importância das abelhas para a biodiversidade, com base no conteúdo do livro didático. Uma escola pública na zona rural foi incluída na pesquisa para avaliar a percepção dos educandos que vivem em ambiente não urbano. O livro didático foi avaliado pelo método qualitativo de análise de conteúdo. A pesquisa quali-quantitativa foi desenvolvida por meio da pesquisa-ação: um questionário estruturado foi aplicado aos educandos antes e depois de uma atividade de sensibilização ambiental. Como resultados observou-se que os livros didáticos não abordaram claramente o papel das abelhas foi aplicado aos educandos antes e depois de uma atividade de sensibilização ambiental. Como resultados observou-se que os livros didáticos não abordaram claramente o papel das abelhas Portanto, a atividade de Educação Ambiental, com a utilização de elementos concretos, contribuiu com a complementação do conteúdo do livro didático sobre as abelhas e com a construção da percepção ambiental crítica dos educandos sobre a importância das abelhas para a biodiversidade.

Palavras-chave: Educação Ambiental; Polinização; Livro Didático.

\section{The importance of bees for the biodiversity in perception of the students from Cáceres, $M T$}

\begin{abstract}
Bees are important pollinators and therefore fundamental to the maintenance of biodiversity. However, a number of anthropogenic changes to the environment have caused a collapse of bees. This study aimed of evaluating the environmental perception of elementary school students of a large public school from Cáceres on the importance of bees for biodiversity, based 0 the contents of the textbook. The textbook was evaluated by the qualitative method of content analysis. The qualitative and quantitative research was developed through action research: a structured questionnaire was administered to students before and after an environmental awareness activity. The result was that textbooks did not clearly address the role of bees in maintaining biodiversity and the causes and consequences of their collapse. After an environmental awareness an improvement in the perception of students about the importance of bees was noted. Therefore, the activity of environmental education, using concrete elements, contributed to the complementation of the textbook contents on the bees and with the construction of the critical environmental perception of students about the importance of bees to biodiversity.
\end{abstract}

Keywords: Environmental Education; Pollination; Textbook.

Topic: Educação Ambiental

Reviewed anonymously in the process of blind peer.
Received: 02/02/2018

Approved: 20/05/2018
Cláudia Lúcia Pinto (iD

Universidade do Estado do Mato Grosso, Brasil http://lattes.cnpq.br/7235493481642242 http://orcid.org/0000-0001-6816-5424 claudia_Ip08@hotmail.com

\section{Aumeri Carlos Bampi (ii)}

Universidade do Estado de Mato Grosso, Brasil http://lattes.cnpq.br/4800812434410023 http://orcid.org/0000-0002-3410-9376

profaumericarlosbampi@gmail.com

\section{Carla Galbiati (iD}

Universidade do Estado de Mato Grosso, Brasil http://lattes.cnpq.br/4449909695203792

http://orcid.org/0000-0001-5442-1562

carla@unemat.br

\section{Referencing this:}

PINTO, C. L.; BAMPI, A. C.; GALBIATI, C.. Importância das abelhas para a biodiversidade na percepção de educandos de Cáceres, MT. Revista Ibero-Americana de Ciências Ambientais, v.9, n.1, p.152-163, 2018. DOI: http://doi.org/10.6008/CBPC2179-6858.2018.001.0011 


\section{INTRODUÇÃO}

O mundo vive uma crise de civilização em virtude do fracionamento do conhecimento e da demanda incontrolável dos recursos naturais. Tal demanda tem ocasionado, nessa busca de recursos, drásticas modificações aos sistemas ecológicos, alterando-os. Nesse processo insere-se uma visão pragmática, seletiva e utilitarista da natureza (LEFF, 2011). Diversos autores ressaltam que os problemas ambientais são frutos do funcionamento do sistema, resultado de um estilo de desenvolvimento insustentável e as consequências ambientais decorrentes disso tende a materializar-se sob formas graves e num ritmo veloz (MARTINS et al., 2011; PINTO et at., 2010; SOUZA et al., 2011). Nesse contexto, a educação formal, com a incorporação da dimensão ambiental em suas práticas, é vista como um processo imprescindível para as transformações da realidade que conduzam a um mundo ambientalmente mais sustentável (MARPICA et al., 2010; MARTINS et al., 2011).

Embora saiba-se que é preciso um conjunto de mudanças civilizatórias (leis, normas, comportamentos, processos de produção), estas não nascem senão de um novo modo de ver, perceber e agir no mundo. A mudança da visão antropocêntrica a uma visão ecocêntrica é necessário, para isso a educação é um processo fundamental e vital. Dentro da educação distinguimos o processo informal e o formal. Tanto um como outro se mostram abertos a processos de aprendizado, no entanto, o processo formal constitui um momento altamente privilegiado para a Educação Ambiental (FERREIRA, 2013; JACOBI, 2003; LEFF, 2009; SILVA et al., 2014).

Neste contexto formal, o livro didático de ciências, particularmente, pode participar deste processo de modo bastante significativo, uma vez que é uma das principais ferramentas utilizadas nos espaços pedagógicos e deve estabelecer uma ligação entre as aprendizagens escolares e a vida cotidiana (CARDOSOSILVA et al., 2013; LAGE et al., 2012; MARPICA et al., 2010). No entanto, segundo Santos (2008), o livro didático não contribui, por si só, com a formação de um cidadão ético, responsável e cooperador com o meio ambiente, o que faz necessário a incorporação de atividades de Educação Ambiental nas práticas pedagógicas. Dessa forma, o professor, como orientador e mediador no processo de ensino e aprendizagem, deve desenvolver um trabalho pedagógico que incentive a crítica, o diálogo e a ação voltada à construção de uma sociedade equilibrada ambientalmente. Para tanto, é necessário investir na formação docente, bem como na formação contínua, em Educação Ambiental (SANTOS et al., 2011).

O desenvolvimento de ferramentas da Educação Ambiental, como a percepção e a sensibilização ambiental, no ambiente escolar é imprescindível, pois estimula a valorização dos aspectos ligados ao meio ambiente no momento em que o conhecimento e o pensamento crítico das crianças, adolescentes e jovens estão sendo formados (OLIVEIRA et al., 2013a). Uma vez que a percepção é definida por Durkheim (2009) como um modo de representação social, o estudo da percepção antes da inserção da sensibilização ambiental é essencial para melhor compreensão das inter-relações entre o homem e o ambiente, suas expectativas, julgamento e condutas (SILVA et al., 2013). 
Dessa forma, a Educação Ambiental contribui com o processo de ensino-aprendizagem dos educandos e, desde cedo, os indivíduos são cultivados a serem sensíveis e conscientes e a atender a necessidade de compreender os problemas ambientais, tanto em seu contexto quanto no contexto global (ALADYM et al., 2014; OLIVEIRA et al., 2013a).

O desenvolvimento de atividades de Educação Ambiental sobre temas específicos, de acordo com a realidade dos educandos, corrobora com a proposta das Diretrizes Curriculares Nacionais para a Educação Ambiental, uma das Diretrizes Curriculares Nacionais da Educação Básica (BRASIL, 2013). Pesquisas de percepção aliadas a atividades de sensibilização têm sido amplamente desenvolvidas em escolas sobre meio ambiente (MALAFAIA et al., 2009; OLIVEIRA et al., 2013b), bem como sobre temas mais específicos, como coleta de lixo e reciclagem (BEZERRA et al. 2014; SILVA et al., 2014), Unidade de Conservação e manguezais (BARCELLOS et al., 2005; CERATI et al., 2009; PEREIRA et al., 2006), morcegos (SILVA et al., 2013) e recursos hídricos (ANTUNES et al., 2014; OLIVEIRA et al., 2013a; PEREIRA et al., 2013; RODRIGUES et al., 2010; SILVA et al., 2014).

Vale ressaltar que os temas ambientais específicos devem ser abordados no contexto da biodiversidade, tendo em vista as inter-relações entre os seres vivos vitais para a manutenção do equilíbrio ambiental. Por exemplo, os insetos, em especial as abelhas, estão diretamente envolvidos em interações ecológicas que oferecem diversos benefícios para a sociedade, como a polinização de inúmeras espécies vegetais (LAGE et al., 2012; SECCO et al., 2011).

As abelhas são consideradas os mais importantes e eficientes polinizadores do mundo, responsáveis pela polinização de 90\% das espécies de plantas com flores (CRUZ et al., 2009; D’AVILA et al., 2005). Na visita às flores para coletar o pólen e o néctar, fonte proteica e energética, respectivamente, as abelhas promovem, involuntariamente, esse serviço ecológico-chave para produção de alimentos, manutenção e conservação dos ecossistemas, assegurando a perpetuação de milhares de espécies de plantas (IMPERATRIZ-FONSECA et al., 2014; PEREIRA et al., 2006; SILVA et al., 2012).

No entanto, um fenômeno tem gerado grande preocupação, a "Desordem de Colapso de Colônias", caracterizado por rápido declínio das populações de abelhas adultas, que leva as colônias ao colapso, visto que são as abelhas adultas fornecem alimentos e mantêm a colmeia. Consequentemente, sem abelhas, ocorre a diminuição da polinização e da produção de frutos, o que leva ao desequilíbrio do ecossistema (IMPERATRIZ-FONSECA et al., 2014). Ainda não há uma explicação definitiva para este fenômeno e algumas pesquisas têm atribuído o desaparecimento das abelhas aos impactos ambientais causados pelos seres humanos, principalmente desmatamentos, queimadas (NAUG, 2009; PEREIRA et al., 2006) e o uso indiscriminado de agrotóxicos (CHAMBÓ et al., 2010; FAROOQUI, 2013).

Visto que os livros didáticos contemplam de forma bastante sucinta a importância das abelhas, as quais sofrem efeitos negativos devido às alterações ambientais provocadas pelo ser humano no ecossistema, e o município de Cáceres se destaca quanto à atividade da apicultura na região do Pantanal, em Mato Grosso, ocupando a segunda posição na produção apícola da região (IBGE, 2014), surgiu o interesse de realizar uma atividade de Educação Ambiental relacionada à importância das abelhas em escolas do município. Nesse 
contexto, esta pesquisa teve o objetivo de avaliar a percepção ambiental dos educandos de uma escola pública de grande porte de Cáceres sobre a importância das abelhas para a biodiversidade, com base no conteúdo do livro didático.

\section{METODOLOGIA}

A pesquisa é de abordagem quali-quantitativa, em que se busca compreender a percepção ambiental dos sujeitos e possibilita a quantificação dos dados (SILVA et al., 2013). Caracteriza-se, pela metodologia de pesquisa-ação, uma modalidade alternativa de pesquisa qualitativa com o intuito de investigar e educar, articulando teoria e prática. A principal característica desta modalidade é a participação e o pesquisador atua como facilitador do grupo de estudo, procurando induzir mudanças sensibilizadoras (SILVA et al., 2013; TOZONI-REIS, 2007).

A pesquisa foi desenvolvida com educandos do ensino fundamental de escola pública, em consonância com a Lei no 9.795/99 (BRASIL, 1999) e as Diretrizes Curriculares Nacionais para a Educação Ambiental (BRASIL, 2013).

O público alvo foram os educandos de duas escolas públicas, uma escola de grande porte para o município de Cáceres (Figura 1). A Escola Estadual "União e Força", localizada no centro do município de Cáceres, oferece o Ensino Fundamental e Médio nos períodos matutino e vespertino e possui em torno de 1050 educandos, com três turmas de 8 o ano no período matutino, com aproximadamente 33 educandos cada. A segunda escola selecionada foi com o intuito de estabelecer um parâmetro de comparação com os educandos da zona rural. A Escola Estadual "Professor João Florentino Silva Neto", classificada como escola do campo, localiza-se no distrito de Caramujo, município de Cáceres, oferece o Ensino Fundamental e Médio nos períodos matutino, vespertino e noturno e possui aproximadamente 400 educandos, com a maioria oriunda de áreas rurais próximas ao distrito. A escola possui duas turmas do 8 o ano com aproximadamente 24 educandos cada.

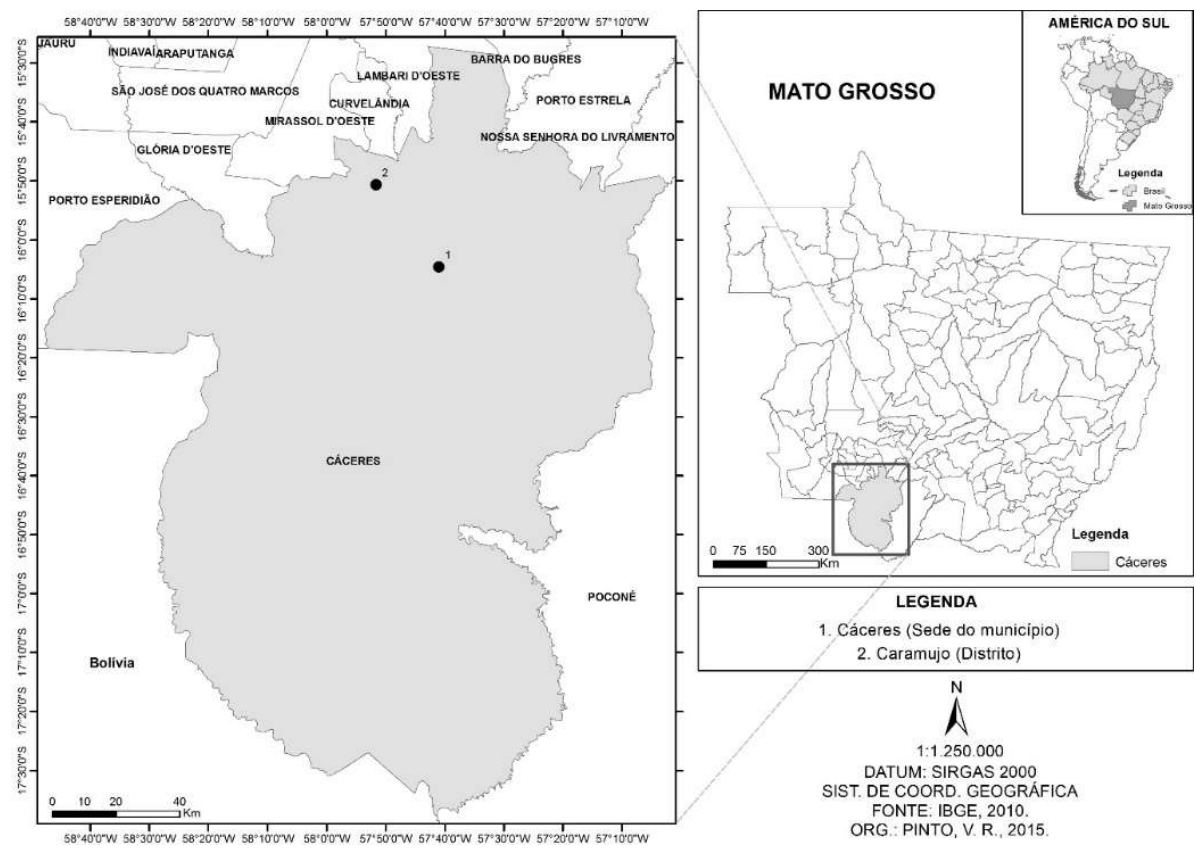


Figura 1. Localização geográfica da sede do município de Cáceres e do distrito de Caramujo, Mato Grosso.

As duas escolas públicas acima mencionadas foram selecionadas por possuírem o maior número de educandos matriculados no 8으 ano na zona urbana e na zona rural em Cáceres e por caracterizarem ambientes escolares diferentes. Isso possibilitou a comparação da percepção dos educandos da zona urbana e zona rural.

As escolas do município de Cáceres foram escolhidas em virtude de ser o maior município da microrregião Alto Pantanal, em Mato Grosso, com população estimada para 2015 de 90.518 habitantes e 14.587 educandos matriculados no ensino fundamental público. Além disso, Cáceres ocupa a segunda posição na produção apícola da microrregião Alto Pantanal, com uma produção anual de $5.150 \mathrm{Kg}$ de mel (IBGE, 2014).

Uma turma de 8o ano foi sorteada, em cada escola, para compor a amostra, tendo em vista que estes educandos estudaram conteúdos relacionados ao meio ambiente nos anos anteriores (6으 e 7으), conforme material didático utilizado pelas escolas. Um total de 22 educandos, 13 da zona urbana e nove da zona rural, com idade entre 13 e 15 anos participou da pesquisa.

Para análise dos livros didáticos do 60 e do 70 ano utilizados pelas referidas escolas (GEWANDSZNAJDER, 2012a; 2012b), os quais abordam conteúdos de meio ambiente e seres vivos, foi utilizado o método qualitativo de análise de conteúdos. Essa forma buscou-se identificar informações nos documentos a partir de questões de interesse (FARIAS et al., 2012; LUDKE et al., 1986; RODRIGUES et al., 2011). Assim, a análise buscou informações nos livros didáticos sobre o conteúdo de abelhas, se os livros abordavam as interações ecológicas que oferecem diversos benefícios para o meio ambiente e para a sociedade, como a polinização por abelhas de inúmeras espécies vegetais e, consequentemente, a manutenção do equilíbrio ambiental, e as causas e consequências do desaparecimento das abelhas. Mediante o resultado desta análise, foi realizada uma atividade de Educação Ambiental constituída em pesquisa de percepção ambiental e sensibilização ambiental.

Para analisar a percepção ambiental dos educandos sobre a importância das abelhas para a biodiversidade, um questionário estruturado com quatro questões objetivas e três discursivas foi aplicado. As questões discursivas permitem ao informante uma maior liberdade de respostas, emitindo sua opinião com as próprias palavras (RODRIGUES et al., 2010). O questionário foi aplicado antes e depois de uma atividade de sensibilização ambiental, no intuito de avaliar a mudança da percepção dos educandos (OLIVEIRA et al., 2013a; SILVA et al., 2013). Além disso, o questionário foi utilizado como instrumento de coleta de dados por ter a vantagem de não exercer pressão sobre o indivíduo, permitindo tempo para reflexão sobre as respostas (CASTOLDI et al., 2009).

A atividade de sensibilização ambiental foi realizada uma semana após a aplicação do questionário, em forma de minicurso sobre a importância das abelhas para a biodiversidade. O minicurso, com duração de 2 horas, foi realizado com a utilização de recursos audiovisuais (laptop e projetor multimídia) para apresentação eletrônica, com socialização de imagens e vídeo, com atenção especial para as limitações e 
curiosidades apresentadas pelos educandos no questionário. Os assuntos abordados foram: definição de biodiversidade, causas e exemplos cotidianos da crise ambiental, polinização por abelhas, produtos apícolas e, principalmente, o desaparecimento das abelhas, com enfoque em suas principais causas e consequências para a biodiversidade e, sobretudo, para o ser humano.

Os educandos propuseram o levantamento de ações para a preservação das abelhas após a apresentação do minicurso. Para finalizar a atividade de sensibilização foram desenvolvidos jogos didáticos relacionados ao tema abordado, constituídos por palavras cruzadas, caça-palavras e trilha, a fim de consolidar o aprendizado dos educandos de forma dinâmica. Em virtude de a atividade ter sido desenvolvida durante a aula de ciências, todos os educandos das turmas selecionadas das duas escolas participaram do minicurso.

Uma semana após a atividade de sensibilização ambiental, o mesmo questionário foi aplicado novamente com o intuito de analisar se houve avanços na sensibilidade dos educandos em relação à importância das abelhas. O projeto foi aprovado pelo Comitê de Ética em Pesquisa da Universidade do Estado de Mato Grosso (CEP/UNEMAT), conforme parecer no 1.065.607, de 14/05/2015.

\section{RESULTADOS E DISCUSSÃO}

Os livros didáticos do ensino fundamental utilizados nas duas escolas públicas de Cáceres (GEWANDSZNAJDER, 2012a; 2012b) contemplou os conteúdos de meio ambiente e as inter-relações existentes entre os seres vivos de forma ampla e a importância das abelhas para a biodiversidade não foi abordada de maneira clara e detalhada. O livro didático do 70 ano (GEWANDSZNAJDER, 2012b) abordou a forma organizacional da colmeia e, brevemente, a associação mutualista entre insetos e plantas foi citada a polinização. O tema do desaparecimento das abelhas não foi abordado nos referidos livros. Isso confirma que a importância ecológica dos insetos, em especial das abelhas, é um assunto abordado superficialmente nos livros didáticos (LAGE et al., 2012), o que faz necessário ampliar essa discussão por meio de atividades complementares.

Os educandos compreendem a importância das abelhas quanto aos serviços ambientais prestados, uma vez que quando foram questionados sobre a importância da preservação das abelhas, houve unanimidade ao assinalarem a opção que diz respeito à sua importância quanto à polinização e conservação da biodiversidade. Além disso, em média $82 \%$ dos educandos tiveram conceitos positivos em relação às abelhas, tais como "importantes", "benéficos" e "que precisamos conservar" (Figura 2). Após a sensibilização a proporção de conceitos positivos aumentou para 93\%. Os conceitos negativos "sem importância" e "que podem ser descartados" não foram citados por nenhum educando. 


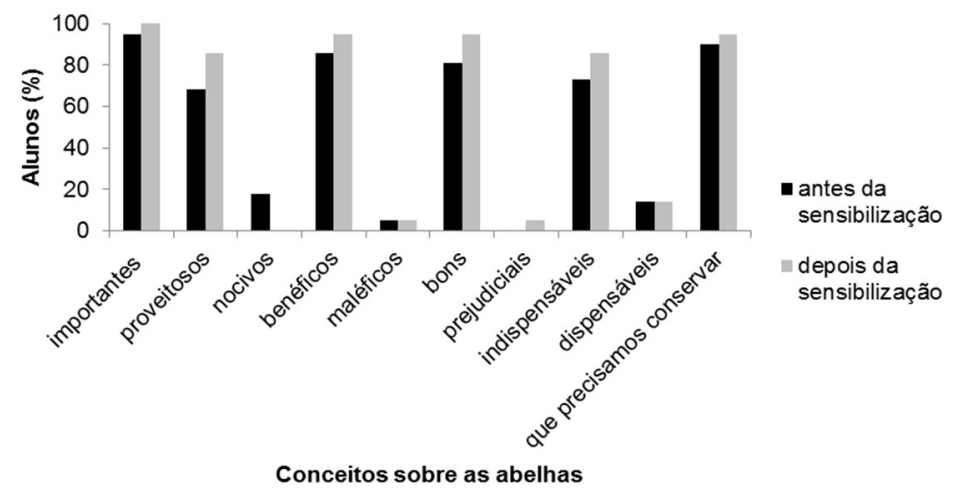

Figura 2. Conceitos sobre as abelhas, segundo a percepção dos educandos do ensino fundamental da escola pública de Cáceres, Mato Grosso.

Quanto à interação entre abelhas e flores, antes da atividade de sensibilização 91\% dos educandos responderam corretamente sobre a interação ecológica, que as abelhas visitam as flores em busca de pólen e néctar para alimentação e realizam, involuntariamente, um importante serviço ambiental, a polinização, conforme abordado no livro didático, e 9\% responderam que as abelhas se alimentam das flores. Após a sensibilização, 95\% dos educandos respondeu corretamente a questão. Essa mudança de percepção ocorreu com educandos da zona rural, visto que os educandos da zona urbana responderam corretamente antes da sensibilização.

Quanto aos fatores que causam impactos ambientais, sobretudo para sobrevivência das abelhas e seu colapso, $41 \%$ dos educandos responderam satisfatoriamente antes da sensibilização (Figura 3), mas $27 \%$ conseguiram explicar a relação entre a destruição da biodiversidade e a destruição das abelhas na questão discursiva. Após a sensibilização, houve mudança na percepção dos educandos e $91 \%$ atribuíram o impacto às abelhas ao desmatamento e ao uso de agrotóxicos (Figura 3). Em questão discursiva, de como a destruição da biodiversidade afeta as abelhas e vice-versa, $77 \%$ dos educandos conseguiram explicar essa relação.

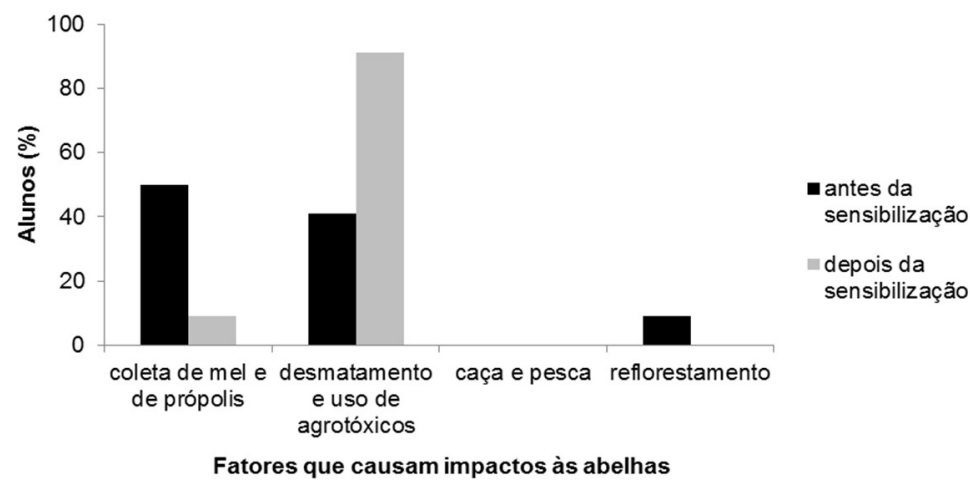

Figura 3. Fatores que causam impactos as abelhas, segundo a percepção dos educandos do ensino fundamental da escola pública de Cáceres, Mato Grosso.

Com uma percepção mais elaborada, após a sensibilização, os educandos relacionaram as abelhas com a biodiversidade no que diz respeito a abrigo, fonte de alimentação e serviço ambiental, como os exemplos que seguem:

"A destruição da biodiversidade afeta as abelhas porque elas ficam sem flores e sem árvores para fazer suas casas e a destruição das abelhas afeta porque elas são importantes para a polinização" (educando da zona urbana). 
"A destruição da biodiversidade afeta as abelhas porque não vai ter flores para elas coletarem o pólen e o néctar. $\mathrm{E}$ a destruição das abelhas afeta a biodiversidade porque se não existirem as abelhas não vai ter polinização" (educando da zona rural).

Na questão discursiva sobre a destruição da biodiversidade sobre as abelhas e vice-versa, os educandos da zona rural, antes da sensibilização, apresentaram percepção mais elaborada, com entendimento sobre a relação de interdependência entre abelhas e biodiversidade. Esses educandos explicitaram que a destruição da biodiversidade afeta as abelhas porque diminui a oferta de recursos alimentares e a destruição das abelhas afeta a biodiversidade porque diminui a polinização. A percepção dos educandos da zona rural pode estar relacionada com o meio onde vivem, observam e constroem sua percepção. Após a atividade de sensibilização, houve avanço na percepção dos educandos, principalmente da zona urbana. Vale ressaltar que uma percepção ambiental incipiente não significa, necessariamente, que o educando não sabe, mas pode ser atribuída a dificuldade de transcrever para o papel suas ideias (OLIVEIRA et al., 2013a).

Em relação aos prejuízos causados pelo desaparecimento das abelhas, $50 \%$ dos educandos indicaram como principal prejuízo a diminuição da produção de mel e $45 \%$ atribuíram que o principal prejuízo está relacionado à conservação da biodiversidade e produção agrícola (Figura 4). Após a sensibilização, houve mudança considerável na percepção dos educandos, quando $73 \%$ dos educandos atribuíram como o maior prejuízo causado pelo desaparecimento das abelhas a redução da produção agrícola e da biodiversidade em geral. A opção "não tem prejuízos, pelo contrário, tem benefícios, porque as abelhas são nocivas" não foi apontada por nenhum educando.

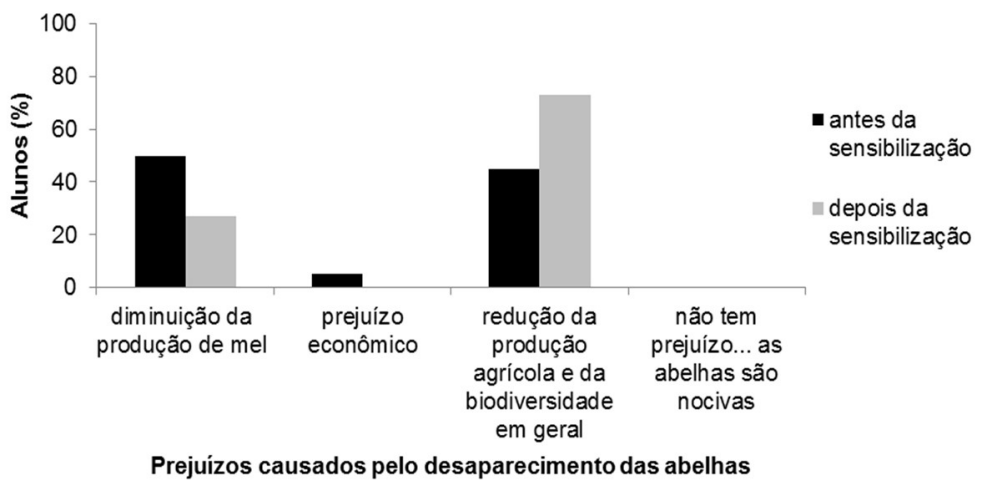

Figura 4. Principais prejuízos causados pelo desaparecimento das abelhas, segundo a percepção dos educandos do ensino fundamental da escola pública de Cáceres, Mato Grosso.

Apesar de o colapso das abelhas ter gerado grande preocupação nos últimos anos, esse fenômeno, bem como suas causas e consequências, não foi abordado pelos livros didáticos, talvez por ser um assunto recente. Nesse sentido, a atividade de sensibilização ambiental contribuiu com a complementação do conteúdo do livro didático.

Quando questionados sobre quais produtos apícolas conheciam, antes da sensibilização, $59 \%$ dos educandos indicaram apenas um produto, o mel, 32\% indicaram dois produtos, sendo mel e própolis ou mel e cera e $9 \%$ dos educandos se referiram a xarope, porém não citaram a partir de qual produto apícola o xarope é elaborado. Após a sensibilização, $27 \%$ dos educandos citaram os cinco produtos apícolas que foram 
apresentados: mel, própolis, geleia real, cera e pólen apícola, 23\% citaram três ou quatro produtos: mel, própolis, geleia real e/ou cera, e 50\% citaram apenas um ou dois: mel e/ou própolis. Quanto ao uso medicinal, tanto antes como depois do minicurso, os mais citados foram gripe, tosse e dor de garganta, também foram citadas asma, bronquite e como anti-inflamatório. Isso mostrou que a atividade de sensibilização contribui para ampliar os serviços ambientais das abelhas além da polinização, ressaltando a importância das abelhas quanto aos produtos apícolas.

O mel e a própolis foram os produtos apícolas mais conhecidos pelos educandos e o minicurso propiciou o conhecimento dos outros produtos apícolas não abordados no livro didático. 0 mel e a própolis são os produtos apícolas mais conhecidos mundialmente e utilizados desde os tempos primordiais da humanidade, e tem ganhado cada vez mais destaque, devido às suas propriedades nutricionais e terapêuticas (BARBOSA et al., 2009; FREITAS et al., 2004). Ao final da atividade de sensibilização, os educandos apontaram algumas ações necessárias para a preservação das abelhas. As ações propostas pelos educandos foram:

"plantar flores; não usar agrotóxicos; evitar queimadas; não destruir nem perturbar as colmeias colocando fogo, jogando pedras ou pedaços de madeira; não destruir as plantas e as flores; evitar desmatamentos" (educandos da zona urbana).

"não desmatar; não provocar queimadas; não usar agrotóxicos; não matar as abelhas; plantar flores" (educandos da zona rural).

Em geral, os educandos da zona rural apresentaram percepção menos elaborada sobre a importância das abelhas do que os educandos da zona urbana antes da atividade de sensibilização ambiental, apesar de conviverem diariamente mais próximos ao meio ambiente. Alguns educandos da zona rural não conseguiam perceber, por exemplo, a interação entre abelhas e flores e quais os fatores que causam impactos ambientais, sobretudo para sobrevivência das abelhas e seu colapso. Acredita-se que o maior conhecimento dos educandos da zona urbana, observado no primeiro questionário seja oriundo da mídia e/ou de outras fontes digitais de informação, uma vez que o material didático utilizado em ambas as escolas foi o mesmo e aborda de forma bem sucinta a importância das abelhas. Além de que, os educandos que vivem na cidade têm mais facilidade no acesso à tecnologia do que os educandos que vivem na zona rural. Com a aplicação do questionário posterior a sensibilização, notou-se mudança na percepção dos educandos, sobretudo da zona rural, com a compreensão das questões ligadas às abelhas no contexto da biodiversidade.

Embora não tenham sido encontrados na literatura estudos que investigaram especificamente a percepção ambiental sobre as abelhas, estudos relacionados à análise da percepção sobre diferentes aspectos ligados ao meio ambiente, acompanhados de atividades de sensibilização ambiental, têm demonstrado resultados positivos quanto ao avanço do conhecimento e sensibilização por parte dos entrevistados, sobretudo, educandos (DEBASTIANI et al., 2016; OLIVEIRA et al., 2013a; PEREIRA et al., 2006; PEREIRA et al., 2013; SILVA et al., 2013; SOUZA et al., 2011).

Conforme Oliveira et al. (2013a), o estudo da percepção aliado a atividades de sensibilização ambiental estimula a valorização dos aspectos ligados ao meio ambiente, favorecendo a preservação e o uso sustentável dos recursos naturais. De acordo com Silva et al. (2013), o desenvolvimento dessas atividades possibilita o crescimento do respeito ao meio ambiente e da responsabilidade individual em atuar, no meio 
em que vive, em busca de algo melhor. Polli et al. (2012) ainda ressaltam que a mudança de hábitos e valores pode ser possível por meio da aplicação de princípios e práticas de Educação Ambiental nos mais diferentes segmentos sociais, sobretudo no contexto escolar quando crianças, adolescentes e jovens estão em fase de construção do conhecimento, pois contribui com o processo de ensino e aprendizagem e com o desenvolvimento de uma consciência ambiental crítica.

\section{CONCLUSÕES}

A percepção ambiental dos educandos de uma escola pública de grande porte de Cáceres foi limitada em relação à importância das abelhas para a biodiversidade. Isso foi atribuído a abordagem de forma bastante sucinta sobre as abelhas no livro didático, sem tratar do o papel das abelhas na manutenção da biodiversidade e as consequências de seu colapso.

A atividade de ensino direcionada à Educação Ambiental contribuiu com a complementação do conteúdo do livro didático sobre o assunto. Após a atividade de sensibilização, notou-se avanço na percepção dos educandos sobre a importância das abelhas para a biodiversidade em termos dos serviços ambientais, da polinização, dos produtos apícolas e dos sérios danos à biodiversidade acarretados pelo desaparecimento dos polinizadores.

Diante dos resultados dessa pesquisa, observa-se que a mudança da percepção ambiental dos educandos do ensino fundamental deve estar associada à formação docente em Educação Ambiental, de forma que a atuação do educador possa suprir as carências do livro didático e proporcionar uma educação sintonizada com a realidade ambiental contemporânea e local.

A atividade de Educação Ambiental foi imprescindível na educação básica diante dos problemas ambientais contemporâneos, devido à falta de contextualização com os entraves para a conservação e preservação do meio, de modo específico, para o entendimento do significado e valor da biodiversidade e, dentro dela, a existência das abelhas. A experiência concreta de Educação Ambiental contribui, consideravelmente, com o processo de aprendizagem e com a formação de uma consciência ambiental crítica dos educandos.

\section{REFERÊNCIAS}

ALAYDIN, E.; DEMIREL, G.; ALTIN, S.; ALTIN, A. Environmental Knowledge of Primary School Students: Zonguldak (Turkey) Example. Procedia - Social and Behavioral Sciences, v. 141, p. 1150-1155, 2014. DOI: http://doi.org/10.1016/i.sbspro.2014.05.195

ANTUNES, C. M. M.; BITTENCOURT, S. C.; RECH, T. D.; OLIVEIRA, A. C.. Qualidade das águas e percepção de moradores sobre um rio urbano. Revista Brasileira de Ciências Ambientais, n. 32, p. 75-87, 2014.

BARBOSA, M. H.; ZUFFI, F. B.; MARUXO, H. B.; JORGE, L. L. R. Therapeutic properties of propolis for treatment of skin lesions. Acta Paulista de Enfermagem, v. 22, n. 3, p. 318-22, 2009. DOI: http://dx.doi.org/10.1590/S010321002009000300013
BARCELLOS, P. A. D. O.; AZEVEDO JUNIOR, S. M.; MUSIS, C. R.; BASTOS, H. F. B. N.. As representações sociais dos professores e alunos Da Escola Municipal Karla Patrícia, Recife, Pernambuco, sobre o manguezal. Ciência \& Educação, v. 11, n. 2, p. 213-222, 2005. DOI: http://dx.doi.org/10.1590/S1516-73132005000200005

BEZERRA, Y. B. S.; PEREIRA, F. D. S. P.; SILVA, A. K. P.; MENDES, D. G. P. S.. Análise da percepção ambiental de estudantes do ensino fundamental II em uma escola do município de Serra Talhada (PE). Revista Brasileira de Educação Ambiental (RevBEA), v. 9, n. 2, p. 472-488, 2014.

BRASIL. Lei № 9.795, de 27 de abril de 1999. Dispõe sobre a Educação Ambiental, institui a Política Nacional de Educação 
Ambiental e dá outras providências. Brasília, DF, 27 de abril de 1999.

BRASIL. Ministério da Educação. Secretaria de Educação Básica. Diretoria de Currículos e Educação Integral. Diretrizes Curriculares Nacionais da Educação Básica. Brasília: MEC, SEB, DICEI, 2013. 562p.

CARDOSO-SILVA, C. B.; OLIVEIRA, A. C. Como os livros didáticos de biologia abordam as diferentes formas de estimar a biodiversidade? Ciência \& Educação, v. 19, n. 1, p. 169-180, 2013. DOI: http://dx.doi.org/10.1590/S151673132013000100012

CASTOLDI, R.; BERNARDI, R.; POLINARSKI, C.A. Percepção dos problemas ambientais por alunos do ensino médio. Revista Brasileira de Ciência, Tecnologia e Sociedade, v. 1, n. 1, p. 56-80, 2009.

CERATI, T. M.; LAZARINI, R. A. M. A pesquisa-ação em educação ambiental: uma experiência no entorno de uma unidade de conservação urbana. Ciência \& Educação, v. 15, n. 2, p. 383-92, 2009. DOI: http://dx.doi.org/10.1590/S151673132009000200009

CHAMBÓ, E. D.; GARCIA, R. C.; OLIVEIRA, N. T. E. DUARTEJÚNIOR, J. B. Aplicação de inseticida e seus impactos sobre a visitação de abelhas (Apis mellifera L.) no girassol (Helianthus annuus L.). Revista Brasileira de Agroecologia, v. 5, n. 1, p. 37-42, 2010.

CRUZ, D. O.; CAMPOS, A. O. Polinização por abelhas em cultivos protegidos. Revista Brasileira de Agrociência, v. 15, n. 1-4, p. 5-10, 2009.

D'AVILA, M.; MARCHINI, L. C. Polinização realizada por abelhas em culturas de importância econômica no Brasil. Boletim de Indústria Animal, v. 62, n. 1, p. 79-90, 2005.

DEBASTIANI, S. M.; TUGOZ, J. E.; BRANDALISE, L. T. A percepção de educandos em relação às ações do PNAE voltadas ao desenvolvimento sustentável. Revista IberoAmericana de Ciências Ambientais (Rica), v.7, n.1, p.6-28, 2016. DOI: http://doi.org/10.6008/SPC21796858.2016.001.0001

\section{DURKHEIM, É. Sociologia e filosofia. São Paulo: Martin} Claret, 2009.

FARIAS, J. G.; BESSA, E.; ARNT, A. M. Comportamento animal no ensino de Biologia: possibilidades e alternativas a partir da análise de livros didáticos de Ensino Médio. Revista Electrónica de Enseñanza de las Ciencias, v. 11, n. 2, p. 365384, 2012.

FAROOQUI, T. A potential link among biogenic amines-based pesticides, learning and memory, and colony collapse disorder: A unique hypothesis. Neurochemistry International, v. 62, p. 122-136, 2013. DOI: http://dx.doi.org/10.1016/j.neuint.2012.09.020

FERREIRA, C. E. A. O meio ambiente na prática de escolas públicas da rede estadual de São Paulo: intenções e possibilidades. Ambiente \& Educação, v. 18, n. 1, p. 185209, 2013.
FREITAS, D. G.F.; KHAN, A. S.; SILVA, L. M. R. Nível tecnológico e rentabilidade de produção de mel de abelha (Apis mellifera) no Ceará. Revista de Economia e Sociologia Rural, v. 42, p. 171-188, 2004. DOI: http://dx.doi.org/10.1590/S0103-20032004000100009

GEWANDSZNAJDER, F. Projeto Teláris. Ciências. Planeta Terra. 1 ed. São Paulo: Ática, 2012a.

GEWANDSZNAJDER, F. Projeto Teláris. Ciências. Vida na Terra. 1 ed. São Paulo: Ática, 2012b.

IBGE. Instituto Brasileiro de Geografia e Estatística. Mato Grosso. 2014.

IMPERATRIZ-FONSECA, V. L.; GONÇALVES, L. S.; JONG, D.; FREITAS, B.; CASTRO, M. S.; SANTOS, I. A.; VENTURIERI, G. C. Abelhas e desenvolvimento rural no Brasil. Mensagem Doce, n. 80, p. 1-13, 2014.

JACOBI, P. Educação ambiental, cidadania e sustentabilidade. Cadernos de Pesquisa, n. 118, p. 189-205, 2003. DOI: http://dx.doi.org/10.1590/S010015742003000100008

LAGE, V. C.; POMPILHO, W. M.; SILVA, F. S. A importância dos livros didáticos para o ensino dos insetos. Revista Práxis, v. 4, n. 7, p. 37-42, 2012.

LEFF, E. Complexidade, interdisciplinaridade e saber ambiental. Olhar de professor, Ponta Grossa, v. 14, n. 2, p. 309-335, 2011. DOI: 10.5212/OlharProfr.v.14i2.0007

LEFF, E. Complexidade, racionalidade ambiental e diálogo de saberes. Educação \& Realidade, v. 34, n. 3, p. 17-24, 2009.

LUDKE, M.; ANDRÉ, M. E. D. A. Pesquisa em educação: abordagens qualitativas. São Paulo: Editora Pedagógica e Universitária, 1986. 99p.

MALAFAIA, G.; RODRIGUES, A. S. L. Percepção ambiental de jovens e adultos de uma escola municipal de ensino fundamental. Revista Brasileira de Biociências, v. 7, n. 3, p. 266-274, 2009.

MARPICA, N. S.; LOGAREZZI, A. J. M. Um panorama das pesquisas sobre livro didático e educação ambiental. Ciência \& Educação, v. 16, n. 1, p. 115-130, 2010. DOI: http://dx.doi.org/10.1590/S1516-73132010000100007 MARTINS, C. T.; HALASZ, M. R. T. Educação ambiental nos manguezais Piraquê-Açú e Piraquê-Mirim. Revista Brasileira de Ciências Ambientais, n. 19, p. 11-17, 2011.

NAUG, D. Nutritional stress due to habitat loss may explain recent honeybee colony colapses. Biological Conservation, v. 142 , p. $2369-2372,2009$. DOI: https://doi.org/10.1016/i.biocon.2009.04.007

OLIVEIRA, E. M.; SANTOS, W. M. B.; MORAIS, J. L.; BASSETTI, F. J.; BERGAMASCO, R. Percepção ambiental e sensibilização de alunos de colégio estadual sobre a preservação de nascente de um rio. REMEA-Revista Eletrônica do Mestrado de Educação Ambiental, v. 30, n. 1, p. 23-37, 2013a.

OLIVEIRA, J. C.; RAMOS, A. C. A.; TEIXEIRA, K. Q.; PERES, M. G.; CARVALHO, W. O. Percepção dos alunos de ensino médio sobre Educação Ambiental em Tefé (AM). Revista Brasileira 
de Educação Ambiental (RevBEA), v. 8, n. 1, p. 130-138, 2013b.

PEREIRA, C. C., SILVA, F. K., RICKEN, I., MARCOMIN, F. E. Percepção e Sensibilização Ambiental como instrumentos à Educação Ambiental. REMEA-Revista Eletrônica do Mestrado de Educação Ambiental, v. 30, n. 2, p. 86-106, 2013.

PEREIRA, D. S.; MEDEIROS, P. V. Q.; GUERRA, A. M. N. M.; SOUSA, A. H.; MENEZES, P. R. Abelhas nativas encontradas em meliponários no oeste Potiguar-RN e proposições sobre seu desaparecimento na natureza. Revista Verde de Agroecologia e Desenvolvimento Sustentável, v. 1, n. 2, p. 54-65, 2006.

PEREIRA, E. M.; FARRAPEIRA, C. M. R.; PINTO, S. L. Percepção e educação ambiental sobre manguezais em escolas públicas da Região Metropolitana do Recife. REMEA-Revista Eletrônica do Mestrado de Educação Ambiental, v. 17, p. 244-261, 2006.

PINTO, V. P. S.; ZACARIAS, R. Crise ambiental: adaptar ou transformar? As diferentes concepções de educação ambiental diante deste dilema. Educação em foco, v. 14, n. 2, p. 39-54, 2010.

POLLI, A.; SIGNORINI, T. A inserção da educação ambiental na prática pedagógica. Ambiente \& Educação, v. 17, n. 2, p. 93-102, 2012.

RODRIGUES, A. S. L.; BÁRBARA, V. F.; MALAFAIA, G. Análise das percepções ambientais e dos conhecimentos de alguns conceitos referentes às nascentes de rios revelados por jovens e adultos de uma escola no município de Ouro Preto, MG. Revista Brasileira de Biociências, v. 8, n. 4, p. 355-361, 2010.

RODRIGUES, M. E.; JUSTINA, L. A. D.; MEGLHIORATTI, F. A. O conteúdo de sistemática e filogenética em livros didáticos do ensino médio. Ensaio Pesquisa em Educação em Ciências, v. 13, n. 2, p. 65-84, 2011. DOI: http://dx.doi.org/10.1590/1983-21172011130205
SANTOS, M. G. F. N. Educação ambiental no livro didático brasileiro. Revista Inter Ação, v. 33, n. 1, p. 49-70, 2008. DOI: https://doi.org/10.5216/ia.v33i1.4242

SANTOS, V. M. N.; JACOBI, P. R. Formação de professores e cidadania: projetos escolares no estudo do ambiente. Educação e Pesquisa, v. 37, n. 2, p. 263-278, 2011. DOI: http://dx.doi.org/10.1590/S1517-97022011000200004

SECCO, M. F. F. V.; SANTOS, J. B. Guia do Educador. Prêmio José Márcio Ayres para jovens naturalistas. 5ed. 2011, 46p.

SILVA, E. A.; OLIVEIRA, C. A. M.; CUNHA, R. R. C. A.; SOARES, R. V. S.; TEIXEIRA, V. D.; GUENTHER, M. Educação Ambiental voltada para a reutilização e reciclagem dos resíduos sólidos no ambiente escolar: um estudo de caso no ensino fundamental em Recife (PE). Revista Brasileira de Educação Ambiental (RevBEA), v. 9, n. 2, p. 412-423, 2014.

SILVA, R. V.; SOUZA, C. A.; BAMPI, A. C. Os olhares dos pescadores profissionais e proprietários comerciais, sobre $o$ Rio Paraguai em Cáceres, Mato Grosso. Revista Brasileira de Ciências Ambientais, n. 32, p. 24-41, 2014.

SILVA, S. G.; MANFRINATO, M. H. V.; ANACLETO, T. C. S. Morcegos: percepção dos alunos do ensino fundamental 3o e 4 ciclos e práticas de educação ambiental. Ciência \& Educação, v. 19, n. 4, p. 859-877, 2013. DOI: http://dx.doi.org/10.1590/S1516-73132013000400006

SILVA, W. P.; PAZ, J. R. L. Abelhas sem ferrão: muito mais do que uma importância econômica. Natureza online, v. 10, n. 03, p. 146-152, 2012.

SOUZA, E. F.; MICHALISZYN, M. S.; OLIVEIRA, C. M. R Educação ambiental, ludicidade e pesquisa participante no ensino fundamental. Revista Brasileira de Ciências Ambientais, n. 21, p. 14-23, 2011.

TOZONI-REIS, M. F. C. A construção coletiva do conhecimento e a pesquisa-ação participativa: compromissos e desafios. Pesquisa em Educação Ambiental, v. 2, n. 2, p. 89-107, 2007. DOI: http://doi.org/10.11606/issn.2177-580X.v2i2p89-107

A CBPC - Companhia Brasileira de Produção Científica (CNPJ: 11.221.422/0001-03) detém os direitos materiais desta publicação. Os direitos referem-se à publicação do trabalho em qualquer parte do mundo, incluindo os direitos às renovações, expansões e disseminações da contribuição, bem como outros direitos subsidiários. Todos os trabalhos publicados eletronicamente poderão posteriormente ser publicados em coletâneas impressas sob coordenação da Sustenere Publishing, da Companhia Brasileira de Produção Científica e seus parceiros autorizados. Os (as) autores (as) preservam os direitos autorais, mas não têm permissão para a publicação da contribuição em outro meio, impresso ou digital, em português ou em tradução. 